\title{
Theoretical Interpretation of Atomic Charge Exchange between Singly Charged Helium Ions and Aluminum Foils
}

\author{
A. A. Mahasneh \\ Department of Applied Physics, Faculty of Science, Tafila Technical University \\ P. O. Box: 179, Tafila 66110 (Jordan)
}

Tel: 96-27-9626-2750 E-mail: d_aamahasneh@yahoo.com

\begin{abstract}
An experimental method for determining the equilibrium charge state of fast helium ions backscattered by solid Al-foils has been conducted using single Silicon Surface Barrier Detector (SBD) in a post acceleration system (PAS). The charge state measurements have been conducted to cover a wide energy range of the incident singly charged helium ion $\mathrm{He}^{+}$. The detected charge states increases from 0 to $+\mathrm{Z}$ with the incident ion's velocity. The method consists of measuring the charge states of ions after backscattering from the Al-foil as a function of projectile velocity and also finding the charge state distributions as a function of Al-foil thickness. The measurements are conducted for two types of Al-foil, one of which is thinner $\left(2.5,4.0,5.4 \mu \mathrm{g} / \mathrm{cm}^{2}\right)$ and the other of which is of the order of an equilibrium foil thickness, where thicknesses of $6.8,8.1,9.5$, and 10.8 were used. Ratios of equilibrium charge state yields for singly to doubly ionized $\mathrm{He}$ ions; $\mathrm{He}^{+1}$ and $\mathrm{He}^{+2}$, were also measured. The kinematics behavior of the measured $\mathrm{He}^{0}, \mathrm{He}^{+}$and $\mathrm{He}^{+2}$ fractions is understood by the well-known Rutherford Backscattering Spectrometry technique (RBS). It has been shown that the dominant processes occurring to a fast $\mathrm{He}^{+}$ions traversing $\mathrm{Al}$-foil are the capture of the electron from the Al-atom to vacant state in the ion and the stripping of the bound electron from the $\mathrm{He}^{+}$ion. The charge composition of the ion beams changes when it backscatters $\mathrm{Al}$-foil, which thick enough for multiple atomic collisions, leading eventually to an equilibrium charge state distribution (ECSD). It was found that the theoretical calculations for electron-capture and loss ratios, based of semi-classical approach of Bianconi, are successful in describing the measured He ions. The satisfactory fits of the measured equilibrium charge state fractions (ECSF's) are mainly accounted to the contribution of both free valance electrons of the target and screened target nucleus in the calculation of total electron-loss cross sections. Bianconi approach is also applied to describe the measured mean equilibrium charges (MEC). The agreement between experiment and theory in this investigation is accounted to the reliability of the used post-acceleration system where all the backscattering charge-states, at certain incident ion's velocity, are separated and collected in one measurement.
\end{abstract}

Keywords: Electron capture, Electron loss, Cross section, Charge state, Mean equilibrium charge

\section{Introduction}

Charge transfer plays an important role for interactions of atoms and ions with solids, and considerable interest in this subject has been devoted in fundamental research as well as technological applications (Armstrong et al., 1965; Betz, 1972; Buck et al., 1973; Robnit et al., 1978; Echenique, 1987; Arnau et al., 1990; Arnau et al., 1994; Itoh et al., 1999; Gojeska et al., 2005; Meharchad et al., 2007). A considerable amount of data can be found in literature related to studies on charge fractions after collisions of atomic projectiles with solid targets. Early work on this problem was concentrated on the analysis of charge state distributions after the transmission of fast ions through thin solid foils or through targets with atoms in the gas phase over a wide domain of projectile velocities (Garnir et al., 1996; Grande \& Schiwietz, 1998; Perumal, 2005), whereas such data for scattering experiments from surfaces of solid targets are rather rare (Bianconi et al., 2002; Ramana et al., 2003; Yang and Jory, 2003; Nakajima et al., 2004). In recent years, however, the impact of atomic projectiles on the surface of solid targets has been paid increased attention, and measurements of charge fractions for energetic projectiles provided the basis for a microscopic understanding of the atom-surface interaction scenario (Kimura et al, 1992; Winter et al., 1998, Wethekam et al., 2003).

The Basic emphasis of the present investigation is to measure the equilibrium charge state fractions of helium ions backscattered from Al-foils ranging in thickness from $2.5 \mu \mathrm{g} / \mathrm{cm}^{2}$ to $10.8 \mu \mathrm{g} / \mathrm{cm}^{2}$. The fractions have been measured using Single SBD in a post-acceleration system. Different theoretical approaches were tested to estimate the measured charge state fractions.

Two fundamental charge exchange processes between ions and target atoms can be distinguished, namely, electron-capture and electron-loss. Experimental measurement of electron capture cross section $\left(\sigma_{\mathrm{C}}\right)$ and electron loss cross section $\left(\sigma_{\mathrm{L}}\right)$ that result from the interaction of light ions with heavier targets has been the matter of 
active research for many years (Soles and Flores, 1988; Soles \& Flores, 1994). At low impact velocities, total capture cross sections are dominated by capture from the outermost target shell. However, as the projectile velocity increases, capture from inner shells plays the main role until, at high enough velocities charge exchange from the target K-shell dominates (Ferrel \& Ritchie, 1977; Maan et al., 1981). Though known and studied since the early days of atomic and sub-atomic physics, the cross sections are still crudely described theoretically. The first description of the electron loss (stripping) process was given by Bohr (1948). Three approximate expressions for $\sigma_{\mathrm{L}}$ have been derived by Bohr (1948) for low, medium, and high atomic number $Z_{\mathrm{T}}$ of the target, in addition, he derived an expression for $\sigma_{\mathrm{C}}$ which is mainly due to electrons having orbital velocities comparable with the velocity of the moving ions.

The charge state distributions of He ions in solids have been investigated experimentally and theoretically in numerous works (Arafah et al., 1989; Arafah et al., 1998; Mahasneh et al., 2007; Mahasneh, 2010). These works highlighted that the equilibrium charge state fractions depend on $\sigma_{\mathrm{C}}$ and $\sigma_{\mathrm{L}}$ (Bohr, 1948; Bohr and Lindhard, 1954; Timmers et al., 2004) nevertheless do not accurately describe all the documented experimentally measured charge state fractions of $\mathrm{He}$ ions in solid targets at different impact velocities. The deviation between experiment and theory is indeed accounted to the complexity of the charge changing processes of energetic ions in the target material. On the other hand, when the incident ion velocity exceeds Bohr's velocity $V_{B}$, the theory shows that the process can be described by single ion-atom collisions, therefore, opening the possibility of the use of more simple approaches developed for the interaction of light ions with target (Bohr, 1948; Bianconi et al., 2002).

Gladieux et al (1979) measured the equilibrium charge state fractions of $\mathrm{He}$ ions that emerge from $\mathrm{C}, \mathrm{Al}, \mathrm{Ni}, \mathrm{Ag}$ and $\mathrm{Au}$ thin targets. Their results are compared with theoretical estimations using capture and loss cross sections of Bohr (1948). Equilibrium charge state distributions for singly and doubly ionized ${ }^{3} \mathrm{He}$ ions have been measured by Dennis et al (1994) for different atomic targets. The ratios of the detected singly and doubly charge state $\left.\mathrm{Y}\left({ }^{3} \mathrm{He}^{+}\right) / \mathrm{Y}^{3} \mathrm{He}^{+2}\right)$ have been measured. The calculated ratios, based on the theoretical stripping and capture cross sections of Bohr, nicely predict the measured ratios. Recently, the equilibrium charge-state fractions of ${ }^{4} \mathrm{He}$ ions transmitted from silicon surface have been measured and then the extracted distributions have been simulated using a semi-classical approach (Bianconi et al., 2002).

Rutherford backscattering and channeling measurements were used to probe the depth distribution and annealing characteristics of the dechanneling yield induced by low-energy ion bombardment. Analysis of the Al surface peak area for channeled $\mathrm{MeV}$ He ions, as well as the dechanneling yield from well below the surface, indicated an unusual increase in the depth distribution of the backscattered ion yield from Al with increasing low-energy He ion dose (Ramana et al., 2003).

He ions with energies from $3 \mathrm{keV}$ to $1.4 \mathrm{MeV}$, which are scattered from a clean $\mathrm{Al}$ (111) surface under a grazing angle of incidence, have been analyzed with respect to charge states (Winter et al., 1998). They observed defined kinematic thresholds for the formation of $\mathrm{He}^{+}$as well as of $\mathrm{He}^{+2}$ ions which are in agreement with the onset of a kinematically induced Auger-ionization process. Comparison of their data with foil transmission experiments shows a clearly different dependence of the charge state fractions on the projectile velocity.

Charge-state distribution of backscattered $\mathrm{He}$ ions was investigated when $400 \mathrm{keV} \mathrm{He}$ ions were incident on three different surfaces; clean $\mathrm{Si}(001)(2 \times 1), \mathrm{SiO}_{2}(2.5 \mathrm{~nm}) / \mathrm{Si}(001)$ and $\mathrm{Ag}(0.31 \mathrm{ML}) / \mathrm{Si}(001)$. The dependence of the charge state on the exit angle of the scattered ions was obtained by measuring the energy spectra of both the scattered $\mathrm{He}^{+}$and $\mathrm{He}^{+2}$ ions at various exit angles for each surface (Nakajima et al., 2004).

This paper has been divided into five parts. In the first part, a brief overview of the recent experimental and theoretical charge state studies has been given. Part two describes the design of the used experimental setup and how the samples were prepared. Part three lays out the theoretical dimension of this study. In part four, the experimental results are discussed and then described theoretically. The main conclusions are summarized in the last part.

\section{RBS Measurements}

The complete description of used experimental setup has been discussed in previous works (Arafah, 1998; Mahasneh et al., 2007) but still brief details are discussed for the sake of continuity. The RBS measurements were carried out with the singly charged ${ }^{4} \mathrm{He}^{+}$beam bended through a $90^{0}$ angle by the analyzing magnet and guided toward the switching magnet. The selected beam was directed into the beam line and passed through a pair of collimators toward scattering chamber where the interactions take place. The beam line and the chamber were evacuated using turbo-molecular pumps until a typical operating pressure of about $10^{-6}$ Torr is reached. The beam enters the RBS chamber via a collimator with a diameter of $1.2 \mathrm{~mm}$ at a distance of $230 \mathrm{~mm}$ in front of the sample. 
Thin Aluminum foils of thicknesses 2.5, 4.0, 5.4, 6.8, 8.1, 9.5, and $10.8 \mu \mathrm{g} / \mathrm{cm}^{2}$ were prepared by vacuum evaporation under an applied pressure of an order of $10^{-6} \mathrm{Torr}$ and evaporation rate of $0.3 \mu \mathrm{g} \mathrm{cm}^{-2} \mathrm{~s}^{-1}$. The foil thickness was measured during evaporation using a crystal oscillator inside the evaporation chamber. Independent measurements conducted by standard RBS using a $2 \mathrm{MeV}$ He beam confirmed the crystal oscillator film thickness data. The foil was then mounted on a target holder inside the RBS scattering chamber shown in Fig. (1) at an angle of $45^{\circ}$ with respect to the beam direction. After the collisions, the backscattered $\mathrm{He}^{\mathrm{k}}(\mathrm{k}=0$, $+1,+2$ ) ions were detected by a SBD of an active area of $100 \mathrm{~mm}^{2}$ placed at $90^{\circ}$ angle with respect to the direction of the incident beam. The distance between the detector and the scattering center was $920 \mathrm{~mm}$ where the solid angle extended by the detector was estimated to be $1.23 * 10^{-4} \mathrm{sr}$. The energy calibration of the SBD was performed with standard samples as well as by changing the incident beam energy, which is known to an accuracy of better than $0.6 \mathrm{keV}$. The accumulated beam charge is measured by a calibrated current integrator. The error in the absolute determination of the scattered particles has been found in various experiments to be less than $6 \%$, i.e, $6 \%$ in the measured neutral fractions and is markedly reduced better than $3 \%$ with higher fractions. The conventional electronics needed for backscattering measurements with SBD were all set at negative potential of $-56 \mathrm{kV}$ relative to ground.

The energy range, where the experiments have been performed, made the charge state distributions less sensitive to surface contamination. The experimental conditions did not cause any noticeable effect of surface contamination, because the vacuum quality prevents the organic vapors that might have been converted into carbon. Typical measurement times to obtain reasonable statistics range from $15 \mathrm{~min}$ to $30 \mathrm{~min}$ depending on the foil thickness. In order to avoid excessive pulse pileup and radiation damage to the detector counting rates during all the measurements were maintained below $80 \mathrm{cps}$. The observations in this experimental work showed that with an additional electrostatic energy of $-56 \mathrm{keV}$ between the target and the SBD, the backscattered ions will gain multiples of this acceleration energy depending on their ionic charge-state $\mathrm{k}$ (i.e., $\mathrm{k} * 56 \mathrm{keV}$ ). The most prominent attribute of the used experimental setup appears clearly in allowing all charge-state fractions, at a certain incident projectile energy, to be collected and measured simultaneously in one experimental run using single SBD.

\section{Theoretical Models}

Basically the charge exchange phenomenon may be described as follows, when a singly charged helium ion passes through matter it suffers a large number of collisions with the atoms of the material, then ionization of either the helium ion or the struck atom may occur, or the helium ion (or the struck atom) may capture an electron. After a large number of such collisions the helium beam becomes charge equilibrated; that is, a definite value (in a statistical sense) for the fraction of the helium beam in each charge state is established (Gojeska et al., 2005; Meharchad et al., 2007). In discussing charge-state fractions for collision systems, two different types of charge changing processes must be considered, namely, electron-capture and electron-loss. The change of the ion charge-state in a target medium is, however, a consequence of a multiple combination of these two types of processes (Ogawa et al., 2000). With regard to electron capture by fast light particles, Bohr points out that, in heavy media that containing electrons of widely different binding energies, the electron capture process is mainly due to electrons having orbital velocities comparable with the velocity of the moving particles. The capture cross section was evaluated by Bohr (1948) as

$$
\sigma_{C}=3 \pi a_{o}^{2} Z_{p}^{5} Z_{T}^{1 / 3}\left(\frac{V}{V_{B}}\right)^{-6}
$$

Here, $\mathrm{a}_{\mathrm{o}}$ and $\mathrm{V}_{\mathrm{B}}$ are the Bohr radius and velocity respectively, and $V$ is the projectile's velocity. $Z_{P}$ and $Z_{T}$ are the atomic numbers of the projectile ion and the target respectively. On the other hand, one of the earliest studies of electron loss cross sections in atomic charge exchange was also carried out by Bohr (1948). For light ions penetrating through foils of high- $Z$ targets a simple estimate for the loss cross section gives

$$
\sigma_{L, B o h r(H i g h-Z)}=\pi a_{o}^{2}
$$

For ion velocities which are larger than the Bohr velocity one can apply the free-collision approximation by neglecting the effect of atomic binding energies. In this approximation Bohr derived 


$$
\sigma_{L, B o h r(L o w-Z)}=\pi a_{o}^{2} \frac{Z_{T}\left(1+Z_{T}\right)}{Z_{P}^{2}}\left(\frac{V}{V_{B}}\right)^{-2}
$$

for low-Z target nuclei. However, for targets with intermediate values of $Z_{T}$, screening effects due to the tightly bound inner electrons leads to the expression

$$
\sigma_{L, B o h r(M i d-Z)}=\pi a_{o}^{2} \frac{Z_{T}^{2 / 3}}{Z_{P}}\left(\frac{V}{V_{B}}\right)^{-1}
$$

Bianconi et al (2002) have developed Bohr classical argument of electron loss process. It has been reported that the electron loss process can be described by a collision between a valence electron, moving at velocity $-\boldsymbol{V}$ and the electron of the ion. The integration over the scattering angles, corresponding to an energy transfer greater than the ionization energy of the ion, gives the loss cross section

$$
\sigma_{L, e-(\text { Bianconi) }}=4 \pi a_{o}^{2} N_{v-e}\left(\frac{V}{V_{B}}\right)^{-4} \times\left[Z_{p}^{-2}\left(\frac{V}{V_{B}}\right)^{2}-1\right]
$$

where $\mathrm{N}_{\mathrm{v}-\mathrm{e}}$ is the number of valence electrons of the target atom $\left(\mathrm{N}_{\mathrm{v}-\mathrm{e}}=3\right.$ for $\left.\mathrm{Al}\right)$. As a matter of fact, the most firmly bound electrons of Al-atom and its nucleus will not, even in close collisions, act independently on the electron carried by the $\mathrm{He}^{+}$ion. The total effect will resemble that of a screened nuclear field. This loss process can be described by the energy transfer from a target atom, moving at velocity $-\mathbf{V}$, colliding with the electron in the ion

$$
\sigma_{L, \text { atom(Bianconi) }}=\frac{2 \pi a_{o}^{2} Z_{T}^{2 / 3}}{e\left(V / V_{B}\right)^{2}}\left[\frac{Z_{p}}{\pi\left(V / V_{B}\right)}-1\right]^{2} \times\left[1-\left(\frac{Z_{p}}{\pi\left(V / V_{B}\right)}-1\right)^{2}\right]^{-1}
$$

where e is the Neper number. Therefore, the total loss-cross section is given by

$$
\sigma_{L, \text { total (Bianconi) }}=\sigma_{L . e-(\text { Bianconi) }}+\sigma_{L, \text { atom (Bianconi) }}
$$

\section{Results and Discussion}

\subsection{RBS Data Acquisition}

To date various methods have been developed and introduced to measure the charge state fractions such as beam transmission, time of flight (TOF), and Rutherford Backscattering Spectrometry (RBS). RBS has proved to be a powerful and versatile technique for surface and near-surface analysis of solids (Williams et al., 1984, Ziegler et al., 1985). RBS is based on the electrostatic repulsion of the nucleus, which causes the beam particles to backscatter after an elastic collision. According to this technique, as an ion beam of incident energy $\mathrm{E}_{0}$ collides with a solid target, a fraction of the incident ions will be scattered backwards through an angle $\theta$ with energy $\mathrm{E}$ from heavier atoms in the near surface region of the target. Therefore, the kinematic factor of the elastic scattering process $\mathrm{K}_{\mathrm{M} 2}$ can be calculated from the ratio of the projectile energy after and before the collision which is given by (Chu et al., 1978)

$$
K_{M 2}\left(M_{1}, M_{2}, \theta\right)=\frac{E}{E_{0}}=\left(M_{1}+M_{2}\right)^{-2}\left[\left(M_{2}^{2}-M_{1}^{2} \sin ^{2} \theta\right)^{1 / 2}+M_{1} \cos \theta\right]^{2}
$$

where $\theta$ is the scattering angle in the laboratory system, $M_{1}$, and $M_{2}$ are the atomic weights of the projectile ion and the target atom, respectively. However, if the scattering angle is $90^{\circ}$, then the kinematic factor $K_{M 2}$ can be written as

$$
K_{M 2}=\frac{M_{2}-M_{1}}{M_{2}+M_{1}}
$$


Two procedures of accumulating the RBS energy spectrum were conducted. In the first procedure, energy spectrum was accumulated without post-acceleration. The spectrum is then fitted by the Gaussian function (Chao, 1974). The second procedure was performed by accumulating the RBS energy spectrum with a fixed post-acceleration voltage, $56 \mathrm{kV}$ in this case. As in the first procedure, the resulting spectrum is fitted by analytical function, which is the sum of weighted function $\mathrm{P}\left(\mathrm{E}+\mathrm{kqV}_{\mathrm{a}}\right)$, according to the following relation (Arafah, 1989):

$$
\left(\left[\sum_{k} A_{k} P\left(E+k q V_{a}\right)\right]-[Y(E)]\right)^{2}=\text { minimum }
$$

where $\mathrm{P}(\mathrm{E})$ is the fitted analytical function without post-acceleration voltage, $\mathrm{E}$ is the energy spanned over the RBS energy spectrum as obtained without post-acceleration, $k$ is the charge state, $q$ is the electronic charge, $A_{k}$ is fitting coefficient for the k-fold charge-state fractional contribution accelerated by an energy of $\mathrm{kqV}_{\mathrm{a}}$, and $\mathrm{Y}(\mathrm{E})$ is the yield corresponding to a RBS spectrum with a fixed post-acceleration voltage $V_{a}$. The charge-state fractions were determined from the total curve fitting to the post-accelerated spectra. In more details, the area under the observed peak due to a certain charge-state, which is obtained from the fitted model, is a measure of its mean charge-state fraction. It is worth to mention that in both procedures the obtained spectra were normalized to the same accumulated charge, i.e., the backscattering yield from a certain depth within the Al-foil is the same, within experimental uncertainties, as that of single isolated peak without post-acceleration. The energy dependence of the peak due to scattering from the surface is, however, governed by the corresponding kinematics equation (Arafah, 1989):

$$
E\left(H e^{k}\right)=K_{M 2} E_{0}+k q V_{a}
$$

where $\mathrm{K}_{\mathrm{M} 2}$ is the RBS kinematic factor, $\mathrm{E}_{0}$ is the incident-ion energy, $\mathrm{k}$ is the charge state, $\mathrm{q}$ is the electronic charge, and $\mathrm{V}_{\mathrm{a}}$ is the acceleration potential. In this study, the PEAKFIT program was employed to perform Gaussian-fitting procedure to give a complete analysis of each measured spectrum.

Fig. 2 (a) shows the RBS energy spectra, with and without acceleration, of He ions backscattered from Al-foils at $600 \mathrm{keV}$ impact energy ( $\mathrm{V}=2.45 \mathrm{a}$. u). Also shown are the results of the fitting procedures representing data with and without post-acceleration. The single isolated peak, which accounts to the backscattering of $\mathrm{He}^{\mathrm{k}}$ ions $(\mathrm{k}=$ $0,+1,+2)$ from $8.1 \mu \mathrm{g} / \mathrm{cm}^{2}$ Al-foil before applying post-acceleration, splits into three distinct peak features after post-acceleration. The well-resolved peaks are corresponding to the charge-states of helium $\left(\mathrm{He}^{0}, \mathrm{He}^{+}\right.$, and $\mathrm{He}^{+2}$ ) and the energy difference between the peaks is always $56 \mathrm{keV}$. The full width at half-maximum (FWHM) of the energy spread of the single peak is the same as those for $\mathrm{He}^{0}, \mathrm{He}^{+}$, and $\mathrm{He}^{+2}$. A considerable overlapping between the charge state fractions is observed which is increased as the Al-foil thickness increases.

On the other hand, at incident energies $>1400 \mathrm{keV}$ (V=3.75 a. u), as shown in Fig. 2(b), the single isolated peak, which refers to He ions backscattering from $8.1 \mu \mathrm{g} / \mathrm{cm}^{2}$ Al-foil at $1800 \mathrm{keV}$ impact energy ( $\left.\mathrm{V}=4.25\right)$, splits into two well-resolved peaks corresponding to $\mathrm{He}^{+}$, and $\mathrm{He}^{+2}$. It was clearly indicated that the approach followed in separating all charge state components ensures that neither the peak shape nor the peak position is disturbed by the analysis, therefore the experimental uncertainties are estimated within $6 \%$ in the measured $\mathrm{He}^{0}$ fractions and the uncertainties are markedly reduced better than $3 \%$ with $\mathrm{He}^{+}$and $\mathrm{He}^{+2}$ fractions. Repeated measurements were done in order to check whether the measured fractions, backscattered from the same thickness at certain impact energy, changed or not. Insignificant changes were found for some repeated measurements.

\subsection{Equilibrium Charge-State Distributions}

When fast singly charged helium ions penetrate a solid Al-foil, the emergent beam is composed of neutral $\mathrm{Y}\left(\mathrm{He}^{0}\right)$, singly $\mathrm{Y}\left(\mathrm{He}^{+}\right)$and doubly charged $\mathrm{Y}\left(\mathrm{He}^{+2}\right)$ fractions. The charge-state distribution is governed by electron capture and loss processes occurring when ions pass through the Al-foil (Bentini et al., 2002; Meharchand et al., 2007). It was found that the charge-state fractions depend on the magnitude of the cross sections for electron-capture $\sigma_{\mathrm{c}}$ and electron-loss $\sigma_{\mathrm{L}}$ of the ions in various charge-states. If we only consider single electron transfer reactions, then the rate of changes of $\mathrm{He}^{+}$and $\mathrm{He}^{+2}$ charge-state fractions with respect to a distance $\mathrm{x}$ traversed in the Al-foil can be simply written as: 


$$
\left.\begin{array}{l}
\frac{d Y\left(H e^{+}\right)}{d x}=N\left[\sigma_{C} Y\left(H e^{+2}\right)-\sigma_{L} Y\left(H e^{+}\right)\right] \\
\frac{d Y\left(H e^{+2}\right)}{d x}=N\left[\sigma_{L} Y\left(H e^{+}\right)-\sigma_{C} Y\left(H e^{+2}\right)\right]
\end{array}\right\}
$$

with the normalization condition $Y\left(H e^{0}\right)+Y\left(H e^{+}\right)+Y\left(H e^{+2}\right)=1 . d Y / d x$ describes the variation of the fraction with the thickness $\mathrm{x}$, and $\mathrm{N}$ is the number of foil atom per unit volume. In the case of equilibrium charge distribution, $\mathrm{He}^{+}$and $\mathrm{He}^{+2}$ fractions backscattered from the Al-foil eventually reach an equilibrium value that does not change as the foil thickness is further increased, therefore

$$
\frac{d Y\left(H e^{+}\right)}{d x}=-\frac{d Y\left(H e^{+2}\right)}{d x}=0
$$

and hence

$$
\frac{Y\left(H e^{+}\right)}{Y\left(H e^{+2}\right)}=\frac{\sigma_{C}}{\sigma_{L}}
$$

A series of charge state distribution measurements was performed with Al-foils having thicknesses of 2.5, 4.0, $5.4,6.8,8.1,9.5$, and $10.8 \mu \mathrm{g} / \mathrm{cm}^{2}$ over a wide domain of projectile energies. Fig. (3) represents the absolute $\mathrm{He}^{0}$ fractions as a function of $\mathrm{Al}$-foil thickness, in the energy range $400-1400 \mathrm{keV}$. No neutral $\mathrm{He}^{0}$ fractions were detected at projectile's energies larger than $1400 \mathrm{keV}$. Throughout the measurement, the incident beam current was very stable and the absolute fraction of the foil-backscattered $\mathrm{He}^{0}$ particles could be determined within the statistical error of 4-6\%. At $800 \mathrm{keV}, 1000 \mathrm{keV}$, and $1400 \mathrm{keV}$ incident projectile's energies, the measured foil-backscattered $\mathrm{He}^{0}$ fractions decay exponentially with the foil thickness in the thinner foil region and converge to an equilibrium value with further increase of the foil thickness, while at $600 \mathrm{keV}$ and $1200 \mathrm{keV}$ the $\mathrm{He}^{0}$ fractions rapidly increase in the thinner region, reach their maximum value at $5.4 \mu \mathrm{g} / \mathrm{cm}^{2}$, and then converge to an equilibrium with further increase of foil thickness. At the lowest projectile's energy; $400 \mathrm{keV}$, the $\mathrm{He}^{0}$ fraction increases in the thinner region until a saturated value of $64 \%$ at $6.8 \mu \mathrm{g} / \mathrm{cm}^{2}$, and stays constant with further increase of the foil thickness.

Fig. (4) shows the absolute $\mathrm{He}^{+}$fractions as a function of $\mathrm{Al}$ foil thickness, in the energy range 400-2800 keV. The statistical errors of the measured $\mathrm{He}^{+}$fractions were less than $3 \%$ for almost all shown points. At $600 \mathrm{keV}$, $800 \mathrm{keV}$, and $1200 \mathrm{keV}$ projectile's energies, the measured foil-backscattered $\mathrm{He}^{+}$fractions decay exponentially with the foil thickness in the thinner foil region and converge to an equilibrium value with further increase of the foil thickness, while at $2800 \mathrm{keV}$ and $1400 \mathrm{keV}$, the $\mathrm{He}^{+}$fractions rapidly increase in the thinner region, reach their maximum values at $4.0 \mu \mathrm{g} / \mathrm{cm}^{2}$, and $5.4 \mu \mathrm{g} / \mathrm{cm}^{2}$ respectively, and then converge to an equilibrium value with further increase of foil thickness. At $400 \mathrm{keV}$, and $1000 \mathrm{keV}$ projectile's energy, the $\mathrm{He}^{+}$fractions decrease in the thinner region, reach their minimum values at $4.0 \mu \mathrm{g} / \mathrm{cm}^{2}$, and then increase until converging to an equilibrium value with further increase of foil thickness. A similar behavior to that at $400 \mathrm{keV}$ and $1000 \mathrm{keV}$ has been found at $1800 \mathrm{keV}$ where the $\mathrm{He}^{+}$fraction reaches its minimum value at $5.4 \mu \mathrm{g} / \mathrm{cm}^{2}$, and then increases until converging to an equilibrium value.

On the other hand, Fig. (5) shows the absolute $\mathrm{He}^{+2}$ fractions as a function of $\mathrm{Al}$ foil thickness, in the energy range $400-2800 \mathrm{keV}$. The absolute fraction of the foil-backscattered $\mathrm{He}^{+2}$ particles could be determined within the statistical error of $2 \%$. At $600 \mathrm{keV}, 800 \mathrm{keV}$, and $1200 \mathrm{keV}$ incident projectile's energies, the $\mathrm{He}^{+2}$ fractions increase with the foil thickness in the thinner foil region and converge to an equilibrium value with further increase of the foil thickness, while at $1400 \mathrm{keV}$, the $\mathrm{He}^{+2}$ fraction rapidly decreases in the thinner region, reaches its minimum values at $5.4 \mu \mathrm{g} / \mathrm{cm}^{2}$, and then increases until converging to an equilibrium value with further increase of foil thickness. At $2800 \mathrm{keV}$, the $\mathrm{He}^{+2}$ fraction has a behavior similar to that at $1400 \mathrm{keV}$ but reaches its minimum value at $4.0 \mu \mathrm{g} / \mathrm{cm}^{2}$. At the lowest projectile's energy; $400 \mathrm{keV}$, the $\mathrm{He}^{+2}$ fraction increases in the thinner region until a saturated value of $38 \%$ at $4 \mu \mathrm{g} / \mathrm{cm}^{2}$, and then increases until converging the equilibrium value.

Fig. (6) illustrates the ratios of equilibrium charge state yields for singly to doubly ionized ions $\mathrm{Y}\left(\mathrm{He}^{+}\right) / \mathrm{Y}\left(\mathrm{He}^{+2}\right)$ in the foil-backscattered beam plotted against Al-foil thickness, in the energy range 400-2800 keV. The complicated behavior of the measured $\mathrm{He}^{+}$and $\mathrm{He}^{+2}$ fractions in the thinner and thick regions (non-equilibrium and equilibrium region) are also extended to the $\mathrm{Y}\left(\mathrm{He}^{+}\right) / \mathrm{Y}\left(\mathrm{He}^{+2}\right)$ ratios. As shown, At $600 \mathrm{keV}, 800 \mathrm{keV}, 1200$ $\mathrm{keV}$, and $1800 \mathrm{keV}$ incident projectile's energies, $\mathrm{Y}\left(\mathrm{He}^{+}\right) / \mathrm{Y}\left(\mathrm{He}^{+2}\right)$ ratio decreases with the foil thickness in the 
thinner foil region and converge to an equilibrium value with further increase of the foil thickness, while at 400 $\mathrm{keV}$, and $1000 \mathrm{keV}, \mathrm{Y}\left(\mathrm{He}^{+}\right) / \mathrm{Y}\left(\mathrm{He}^{+2}\right)$ ratio decreases in the thinner region, reaches its minimum values at 4.0 $\mu \mathrm{g} / \mathrm{cm}^{2}$, and then increases until converging to an equilibrium value. At $2800 \mathrm{keV}, \mathrm{Y}\left(\mathrm{He}^{+}\right) / \mathrm{Y}\left(\mathrm{He}^{+2}\right) \mathrm{ratio}$ increases, reaches its maximum value at $4.0 \mu \mathrm{g} / \mathrm{cm}^{2}$ and then decreases until converging an equilibrium value. At $1400 \mathrm{keV}, \mathrm{Y}\left(\mathrm{He}^{+}\right) / \mathrm{Y}\left(\mathrm{He}^{+2}\right)$ ratio has a behavior similar to that at $2800 \mathrm{keV}$ but reaches its maximum value at 5.4 $\mu \mathrm{g} / \mathrm{cm}^{2}$.

The most striking result to emerge from the analysis of the measured RBS energy spectra at different impact energies is the ECSD's, where the variation of the charge state fractions during the passage of depth $\mathrm{x}$ ceases; $\mathrm{dY} / \mathrm{dx} \rightarrow 0$, as $\mathrm{x}$ increased. From the data in Figs (3-6), it is clearly apparent that the charge states of He ions backscattered from Al-foils of thicknesses $\geq 6.8 \mu \mathrm{g} / \mathrm{cm}^{2}$, within the experimental error, represent the ECSF's, while the charge states backscattered from thicknesses less than $6.8 \mu \mathrm{g} / \mathrm{cm}^{2}$ represent the non ECSF's since there are differences in their distributions. As a consequence, The complicated behavior of the backscattered $\mathrm{He}^{0}, \mathrm{He}^{+}$, and $\mathrm{He}^{+2}$ fractions, as well as of the measured $\mathrm{Y}\left(\mathrm{He}^{+}\right) / \mathrm{Y}\left(\mathrm{He}^{+2}\right)$ ratios, which is clearly indicated in the thinner foil region (non-equilibrium region), is mainly accounted to the complication of the electron capture from Al-atom by $\mathrm{He}^{+}$ion and the electron stripping from the $\mathrm{He}^{+}$ion by the $\mathrm{Al}$-atom, therefore, a theoretical interpretation of the measured fractions is highly recommend and important. Form Eq.14, the measured $\mathrm{Y}\left(\mathrm{He}^{+}\right) / \mathrm{Y}\left(\mathrm{He}^{+2}\right)$ ratios can be compared with the theoretical ratios $\left(\sigma_{\mathrm{C}} / \sigma_{\mathrm{L}}\right)$ estimated by Bohr theory (1948) and Bianconi semi-classical model (Bianconi et al., 2002)



The measured $\mathrm{Y}\left(\mathrm{He}^{+}\right) / \mathrm{Y}\left(\mathrm{He}^{+2}\right)$ ratios and the calculated ratios $\left(\sigma_{\mathrm{C}} / \sigma_{\mathrm{L}}\right)$ as a function of projectile's velocity are illustrated with Fig. (7). As shown, $\left(\sigma_{\mathrm{C}} / \sigma_{\mathrm{L}}\right)$ of Bianconi nicely estimates the measured $\mathrm{Y}\left(\mathrm{He}^{+}\right) / \mathrm{Y}\left(\mathrm{He}^{+2}\right) \mathrm{ratios}$ better than Bohr model for High-Z and Mid-Z targets.

\subsection{Simulation of Equilibrium Charge State Fractions}

The neutral measured $\mathrm{He}^{0}$ fractions backscattered from $8.1 \mu \mathrm{g} / \mathrm{cm}^{2}$ are plotted in Fig. (8) against the projectile's velocity (a. u). These fractions can be reasonably fitted by the exponential function

$$
Y\left(H e^{0}\right)=(59.8 \pm 1.42) \exp \left[-(1.13 \pm 0.2)\left(\frac{V}{V_{B}}\right)\right]
$$

and this relation is only valid within the limited domain of derivation. On the other hand, the measured $\mathrm{He}^{+}$and $\mathrm{He}^{+2}$ fractions backscattered from $8.1 \mu \mathrm{g} . \mathrm{cm}^{-2}$ Al-foil over a wide domain of projectile velocity are shown in Fig. (9).

From the normalization condition $Y\left(H e^{o}\right)+Y\left(H e^{+}\right)+Y\left(H e^{+2}\right)=1$, the singly and doubly charged helium fractions; $Y\left(\mathrm{He}^{+}\right)$and $Y\left(\mathrm{He}^{+2}\right)$ are given respectively by:

$$
\begin{aligned}
& Y\left(H e^{+}\right)=\left(\frac{Y\left(H e^{+}\right)}{Y\left(H e^{+2}\right)}\right)\left[\frac{1-\left(59.8 \exp \left(-1.13\left(V / V_{B}\right)\right)\right.}{1+\left[Y\left(H e^{+}\right) / Y\left(H e^{+2}\right)\right]}\right] \\
& Y\left(H e^{+2}\right)=\left[\frac{1-\left(59.8 \exp \left(-1.13\left(V / V_{B}\right)\right)\right.}{1+\left[Y\left(H e^{+}\right) / Y\left(H e^{+2}\right)\right]}\right]
\end{aligned}
$$

Using equations 15 (a-c), the $H e^{+}$and $H e^{+2}$ fractions can be simulated respectively by 


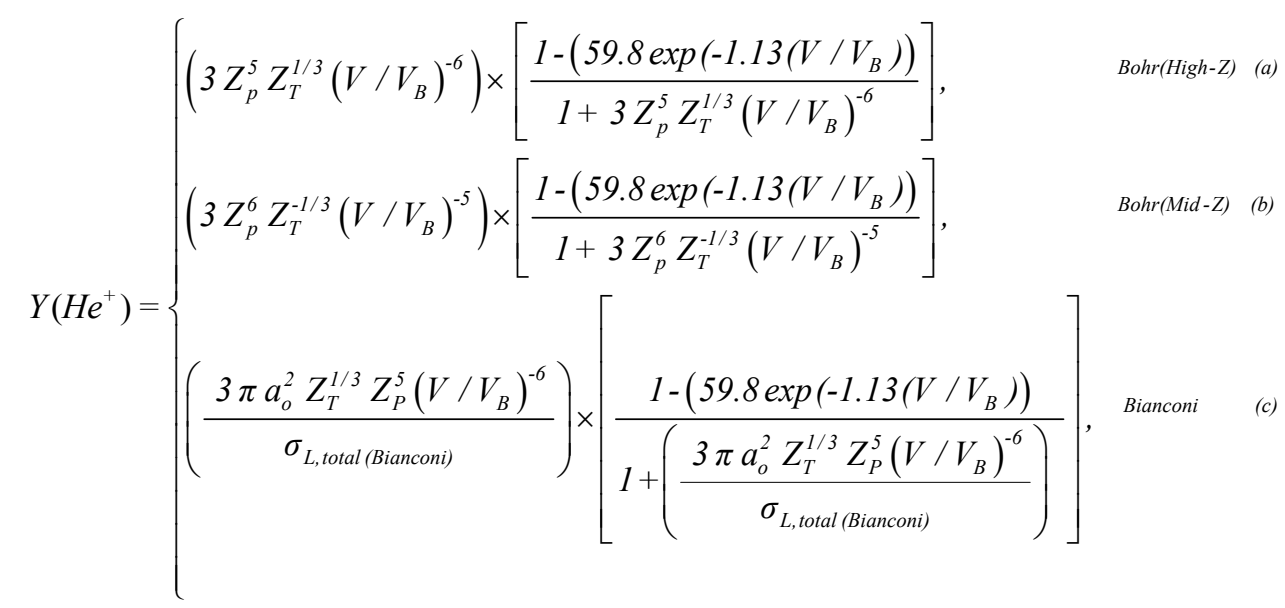

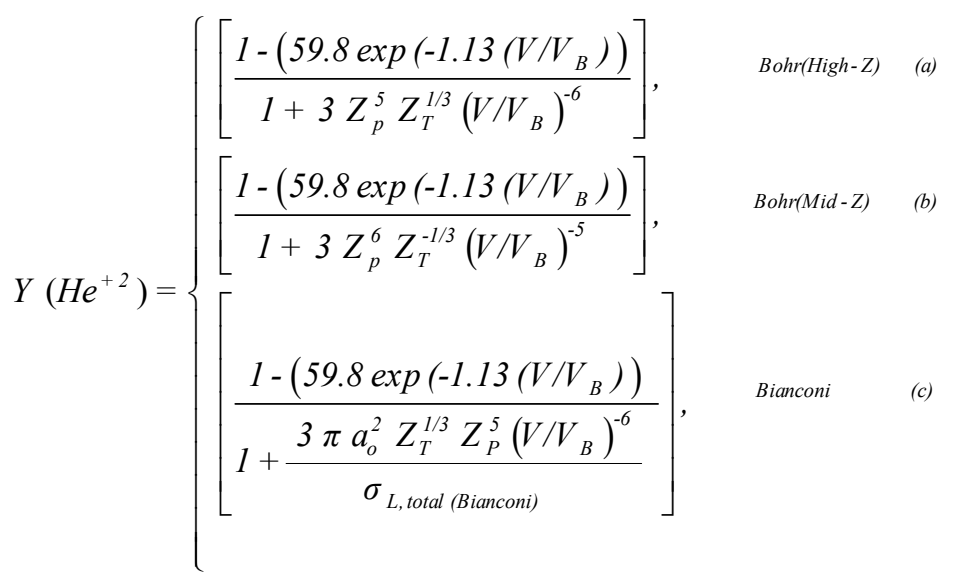

Fig. (9) also shows $\mathrm{He}^{+}$and $\mathrm{He}^{+2}$ fractions simulated by equation groups 19 and 20. It is clearly shown that as the incident projectile velocity increases, the doubly charged fraction increases and become dominate at incident energy $\geq 2000 \mathrm{keV}(\mathrm{V}=4.48 \mathrm{a} . \mathrm{u}$ ), and this is accounted to the fact that at high velocities the projectile ion spends little time near the target, therefore, the interaction is swiftly completed and the projectile's electron is stripped off by the $\mathrm{Al}$ atom since the electrons in the conduction band do not have enough time to screen the incoming energetic ion (Soles and Flores, 1986). The singly and doubly charged helium fractions are nicely fitted by Bianconi model better than Bohr model of High- $Z$ and Mid-Z targets. On the other hand, the relative importance of the singly charged fractions is strongly decreased as the projectile velocity increases, and this is attributed to the fact that at low velocities, the projectile ions spend enough time near the target atom and as a result their probabilities to capture an electron from the target are large. At energies larger than $2400 \mathrm{keV} \quad(\mathrm{V}=$ 4.9 a. u), the backscattered beam are almost fully stripped and the fractions are nicely described by the semi classical approach of Bianconi as well as by the classical approach of Bohr for High-Z and Mid-Z targets.

\subsection{Simulation of the Backscattered Mean Equilibrium Charge}

Various semi-empirical or empirical formulas for mean charge of ions after passage through solid foils have been proposed (Shima et al., 1986; Itoh et al., 1999; Tordior et al., 2001). Each of them is valid within the limited domain of derivation. In general, the mean charge is given by

$$
Q_{m}=\sum_{k=0} k Y\left(A^{+k}\right)
$$

Where $\mathrm{k}$ is the charge state, $\mathrm{A}^{+\mathrm{k}}$ are the measured ions, and $\mathrm{Y}\left(\mathrm{A}^{+\mathrm{k}}\right)$ is the normalized yield of the measured ions. Hence, all available experimental data of mean equilibrium charge backscattered from $8.1 \mu \mathrm{g} / \mathrm{cm}^{2} \mathrm{Al}$-foil are well estimated by 


$$
Q_{m_{\left(H e^{+} \rightarrow A l\right)}}=Y\left(H e^{+}\right)+2 Y\left(H e^{+2}\right)
$$

The measured mean equilibrium charge can be simulated by Bianconi, model and Bohr model for High-Z and Mid-Z targets. Hence, Substitution of equation groups 19 and 20 in Eq. (22) leads to a new expression for the mean equilibrium charge

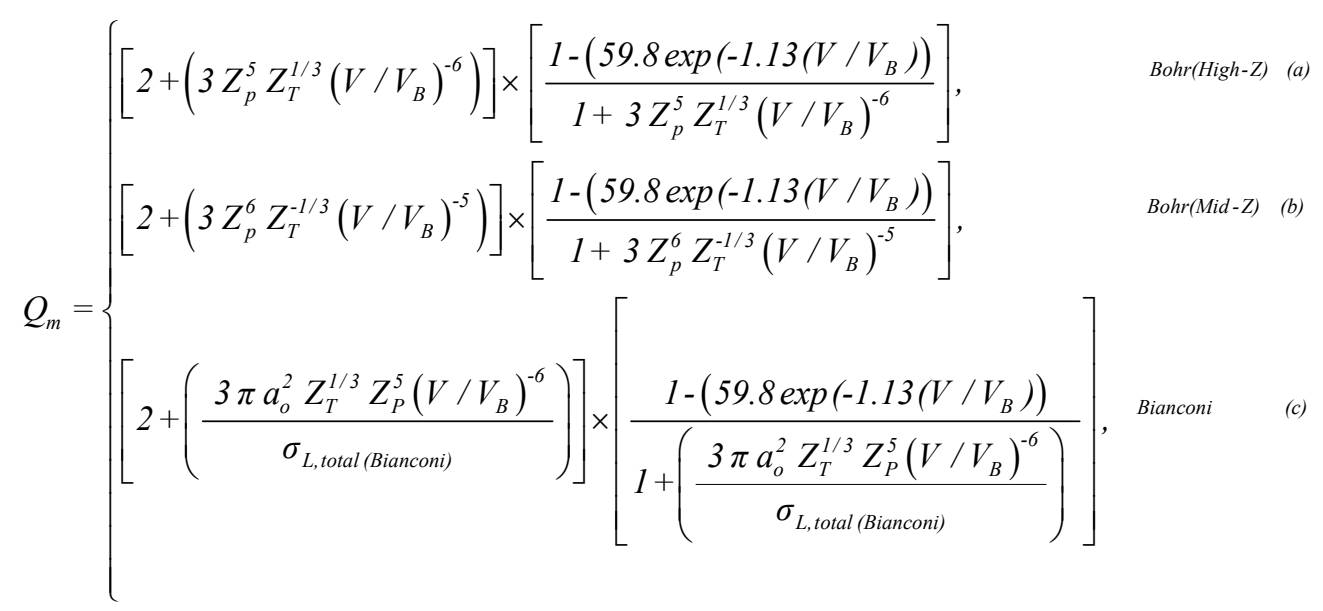

As shown in Fig. (10), the measured fractions are well described by Bianconi model. To assist the evaluation of the mean equilibrium charge at higher velocities, $\left(2-\mathrm{Q}_{\mathrm{m}}\right) * 10$ is also plotted.

\section{Conclusion}

Equilibrium charge-state fractions of ${ }^{4} \mathrm{He}$ ions backscattered from Al-foils have been measured for thicknesses ranging between $\left(2.5-10.8 \mu \mathrm{g} / \mathrm{cm}^{2}\right)$ over a wide domain of projectile energies. The measured fractions have been interpreted theoretically using the extended Bohr theory. It was found that the charge-states of $\mathrm{He}$ ions backscattered from Al-foils of thicknesses $\geq 6.8 \mu \mathrm{g} . \mathrm{cm}^{-2}$, within the experimental errors, represent the equilibrium charge state distributions, while the charge-states backscattered from thicknesses less than 6.8 $\mu \mathrm{g} / \mathrm{cm}^{2}$ represent the non-equilibrium charge state distributions. The energy range, where our experiments have been performed, made the charge state distributions less sensitive to surface contamination. The experimental uncertainties, in the present work, are estimated within $6 \%$ in the measured neutral fractions and the uncertainties are markedly reduced better than $3 \%$ with higher fractions.

The simulations, which have been obtained in this work, predict well the experimental data within the studied energy range. The agreement between experiment and theory is accounted to the reliability of the used post-acceleration system where all the backscattering charge-states, at certain impact energy, are separated and collected in one measurement. The applicability of the extended Bohr theory for $\mathrm{He}^{+}-\mathrm{Al}$ pair is also supported by applying the same simulation procedures to $\mathrm{He}^{+}-\mathrm{Ag}$ pair where a good agreement between the measured and simulated fractions has been noticed. Consequently, this research has thrown up many questions in need of further investigation, and will serve as a base for future studies. Further investigation and experimentation into charge-state determination for different targets at different impact energies of incident ions is strongly recommended. Experimental investigations are also needed to study dependence of the measured charge-state fractions on the scattering angle.

\section{Acknowledgement}

I would like to thank Prof. Dr. Dia-Eddin Arafah from Jordan University for his continuous support. The efforts of the technical staff at JUVAC are also highly appreciated.

\section{References}

Armstrong, J. C., Mullendore, J. V., Harris, W. H., and Marion, J.B. (1965). Equilibrium charge-state fractions of 0.2 to $6.5 \mathrm{MeV}$ helium ions in carbon. Phys. Soc. 86, pp. 1283-1295.

Arafah, D.-E. (1998). Equilibrium Charge state Fractions and distributiuons of ${ }^{4} \mathrm{He}$ ions backscattered from gold films. Nuovo. Cimento., 20, pp. 261-271. 
Arafah, D.-E., Meyer, J.D., Sharabati, H., and Mahmoud, A. (1989). Charge-state measurements of backscattered ions from Au films. Physical Review A, 39, pp. 3836-3841.

Arnau, A. (1994). Charge states and energy loss of ions in solids. Nuclear Instruments and Methods B, 93 (1994) 195.

Arnau, A., M. Pealba, M., and Echenique, P.M., Flores, F., and Ritchie, R.H. (1990). Stopping power for helium in aluminum. Phys. Rev. Lett., 65, pp. 1024-1027.

Baudinet-Robinet, Y., Dumont, P.D., and Garnir, H. P. (1978). Analysis of charge-state distributions of heavy ions in carbon foils and gases. J. Phys. B: Atom. Molec. Phys, 11, pp.1291-1302.

Bentini, G. G., Abertazzi, E., Bianconi, M., Lotti, R., and Lulli. G. (2002). Charge states distribution of 3350 $\mathrm{keV}$ He ions channeled in silicon. Nuclear Instruments and Methods B, 193, pp. 113-117.

Betz, H.D. (1972). Charge States and Charge-Changing Cross Sections of Fast Heavy Ions Penetrating Through Gaseous and Solid Media. Rev. Mod. Phys., 44, pp. 465-539.

Bianconi, M., Bentini, G.G., Lotti, R., and Nipoti, R. (2002). Charge states distribution of $\quad 0.16-3.3 \mathrm{MeV} \mathrm{He}$ ions transmitted through silicon. Nuclear Instruments and Methods B, 193, pp. 66-70.

Bohr, N. (1948). "The Penetration of Atomic Particles through Matter", Mat. Fys. Medd. Dan. Vid. Selsk., 18 (8), pp. 1-144.

Bohr, N., Lindhard, J. (1954). Electron capture and loss by heavy ions penetrating through matter. Mat. Fys. Medd. Dan. Vid. Selsk., 28 (7), pp. 1-31.

Buck, T.M., Wheatley, G.H., and Feldman, L.C. (1973). Charge states of $25-150 \mathrm{keV}$ H and ${ }^{4} \mathrm{He}$ backscattered from solid surfaces. Surface Science, pp. 345-361.

Chao, L.L. (1974). Statistics Methods and Analys. $2^{\text {nd }}$ edition. Tokyo: McGraw-Hill Kogakusha, LTD.

Chu, W.K., Mayer, J.W. and Nicolet, M.A. (1978). Backscattering Spectrometry. New York: Academic Press, Inc.

Dennis, K,. Akimune, Berg, H., Chang, S., Davis, B., Fujiwara, M., Harakeh, M. N., Jänecke, J., Pham, J., Roberts, D. A., and Stephenson, E. J. (1994). Atomic charge exchange between fast helium ions and targets from carbon to bismuth at $\beta=0.36$. Phys. Rev. A, 50, pp. 3992-3999

Echenique, P. M. (1987). Interaction of slow ions with bulk and surfaces. Nuclear Instruments and Methods B, 27 , pp. 256-265.

Ferrell, T. L., and Ritchie, R. H. (1977). Energy losses by slow ions and atoms to electronic excitation in solids. Phys. Rev. B, 16, pp. 115-122.

Garnir, H.P., Bastin, T., and Dumont, P. D. (1996). Life-time measurement by beam-foil spectroscopy. Physica Scripta. T65, pp. 36-42.

Galdieux, A., Chateau-Thierry, A., and Delaunay, B. (1979). Experimental charge fractions in helium beams emerging from solids. Journal of Physics B: Atomic and Molecular Physics, 12 (21), pp. 3591.

Gójska, A., Chmielewska, D., Rzadkiewicz, J., Sujkowski, Z., Adachi, T., Fujita, T., Fujita, Y., Hara, K., Haruyama, Y., Kamiya, J., Ogawa, H., Saito, M., Shimizu, Y., Shimbara, Y., Tanaka, M., Yoshida, H.P., and Katayama, I. (2005). Charge exchange processes for semi-relativistic helium ions $(\beta=0.51)$ in solid gold. Nuclear Instruments and Methods B, 235, pp. 368-373.

Grande, P., Schiwietz, G. (1998). Channeling energy loss of O ions in Si: The Barkas effect. Nuclear Instruments and Methods B, 125, pp.136-138.

Itoh, A., Tsuchida, H., Majima, T., Yogo A., and Ogawa, A. (1999). Equilibrium charge distributions of lithium ions emerging from a carbon foil. Nuclear Instruments and Methods B, 159, pp. 22-27.

Kimura, K., Ohatsuka, H., and Mannami, M. (1992). Charge-State of Distribution of MeV He Ions Scattered from the Topmost Atomic Layer of the SnTe(001) Surface. Physical Review Letter , 68 (28), pp. 3797-3800.

Maan, A., and Brandt, W. (1981). Material dependence of low-velocity stopping powers. Phys. Rev. B, 24, pp. 4999-5003.

Mahasneh, A. A., Ajlouni, A. W., and Abu-Haija, O. (2007). Distributions of $0.125-0.50 \mathrm{MeV} / \mathrm{amu}{ }^{4} \mathrm{He}$ Ions Backscattered from Metallic Surface. Journal of Applied Sciences (JAS), 7, 1497-1503 
Mahasneh, A. A. (2010). Theoritical Description of Equilibrium Charge-State Fractions in Helium Beams Backscattering from Gold-Foils. European Journal of Scientific Research, 42 No. (3).

Meharchand, R., Akimune, H., Van den Berg, Fujita, A.M., Fujiwara, Y., Gale, S., Harakeh, M.N., Hashimoto, H., Hayami, R., Hitt, G.W., Itoh, M., Kawabata,T., Kawase, k., Kinoshita, M., Nakanishi,k., Nakayama,S., Okumura, S., Shimbara, Y., Uchida, M., Yamagata, T., Yosoi, M., Zegers, R.G.T., 2007. Atomic charge-exchange between semi-relativistic $(\mathrm{v} / \mathrm{c}=0.49)$ helium ions and targets from carbon to lead. Nuclear Instruments and Methods B, 264, pp. 221-226.

Nakajima, K., Okura, Y., Suzuki, M., and Kimura, K. (2004). Charge-state distribution of $400 \mathrm{keV}$ He ions scattered from solid surfaces. Nuclear Instruments and Methods B, 219-220, pp. 514-518.

Ogawa, H., Sakamoto, N., Shiomi-Tsuda, N., and Tsuchida, H. (2000). Emergent-angle-dependent charge-state distributions of 2-MeV ${ }^{4} \mathrm{He}$ transmitted through a thin carbon foil. Phys. Rev. A, 61, 032717, 6 pages.

Perumal, A.N., Horvat, V., Watson, R.L., Peng, Y. , and Fruchey, K.S. (2005). Cross sections for charge change in argon and equilibrium charge states of $3.5 \mathrm{MeV} / \mathrm{amu}$ uranium ions passing through argon and carbon targets. Nuclear Instruments and Methods B, 227, pp. 251-260.

Ramana, C. V., Choi, B.S., and Smith, R.J. (2003). Low-energy ion-beam induced effects in $\mathrm{Al}\left(\begin{array}{ll}10 & 0\end{array}\right)$ surfacestudied using Rutherford backscattering and channeling. Nuclear Instruments and Methods B, 214, pp. 338-350.

Shima, K., Mikumo, T., and Tawara, H. (1986). Equilibrium charge state distributions of ions $\left(Z_{1} \geq 4\right)$ after passage through foils. Atomic data and nuclear data tables, 34, pp. 357-391.

Sols, F., and Flores, F. (1986). Charge state distributions for ions moving in metals. Nuclear Instruments and Methods B, 13, pp. 171-174.

Sols, F., and Flores, F. (1988). Inelastic cross sections and charge states for B, C, N, and O ions moving in metals. Physical Review A, 37 , pp.1469-1475.

Sols, F., and Flores, F. (1994). Charge transfer processes for light ions moving in metals. Physical Review B, 30 (8), pp. 4878-4880.

Timmers, H., Li, M., and O'Connor, D.J. (2004). A study of the charge state approach to the stopping power of $\mathrm{MeV}$ B, N and O ions in carbon", Nuclear Instruments and Methods B, 222, pp.11-18.

Tordoir, X., Bastin, T., Dumont, P.-D., and Garnir, H.P. (2001). Equilibrium charge-state distributions of sodium ions in carbon. Nuclear Instruments and Methods B, 173 (2001) 275-280.

Williams, J.S., and Poate, J.M. (1984). Ion Implication and Beam Processing. Australia: Academic Press.

Wethekam, S., Mertens, A., and Winter, H. (2003). Charge states of multicharged Cs ions after grazing scattering from a $\mathrm{Cu}(111)$ surface. Physics Letters A 316, pp.324-328.

Winter, H., Siekmann, G., Ortjohan, H. W., Poizat, J. C., and Remillieux J. (1998). Charge state distributions after the scattering of fast $\mathrm{He}+$-ions from an $\mathrm{Al}(111)$-surface under a grazing angle of incidence. Nuclear Instruments and Methods B, 135, pp. 372-376.

Yang, Y., and Jory, A. (2003). Effects of adsorbates on charge exchange in $\mathrm{Li}+$ ion scattering from $\mathrm{Ni}(100)$. Journal of Vacuum Science \& Technology, A. 21 (4), pp. 1317-1321.

Ziegler, J.F, Biersack, J.P and Littmark, N. (1985). The Stopping and Range of Ions in Solids. New York: Pergamon Press. 




Figure 1. RBS scattering chamber with a Surface Barrier Detector and conventional electronics needed for backscattering measurements.

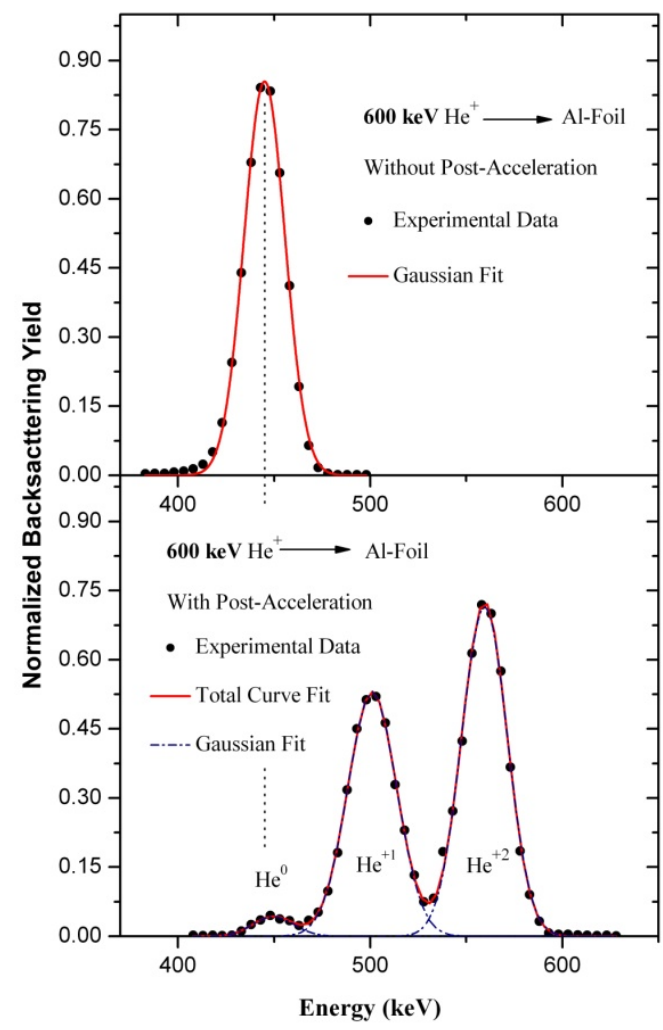

(a)

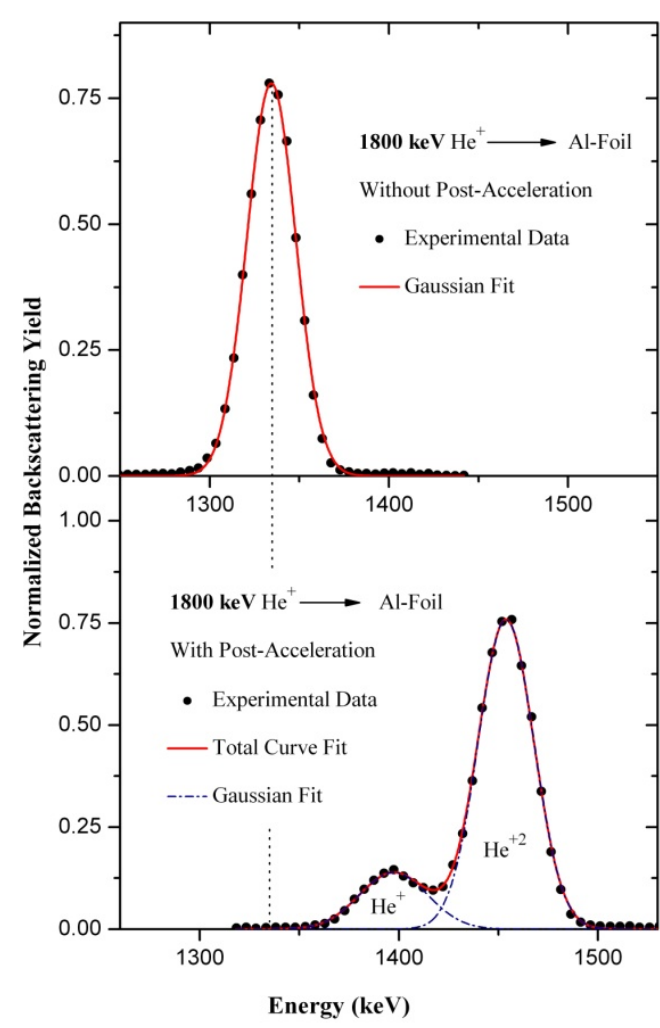

(b)

Figure 2. RBS energy Spectra of He ions backscattered from $8.1 \mu \mathrm{g} / \mathrm{cm}^{2} \mathrm{Al}$-foil at impact energies of: (a) $600 \mathrm{keV}$ and (b) $1800 \mathrm{keV}$. 


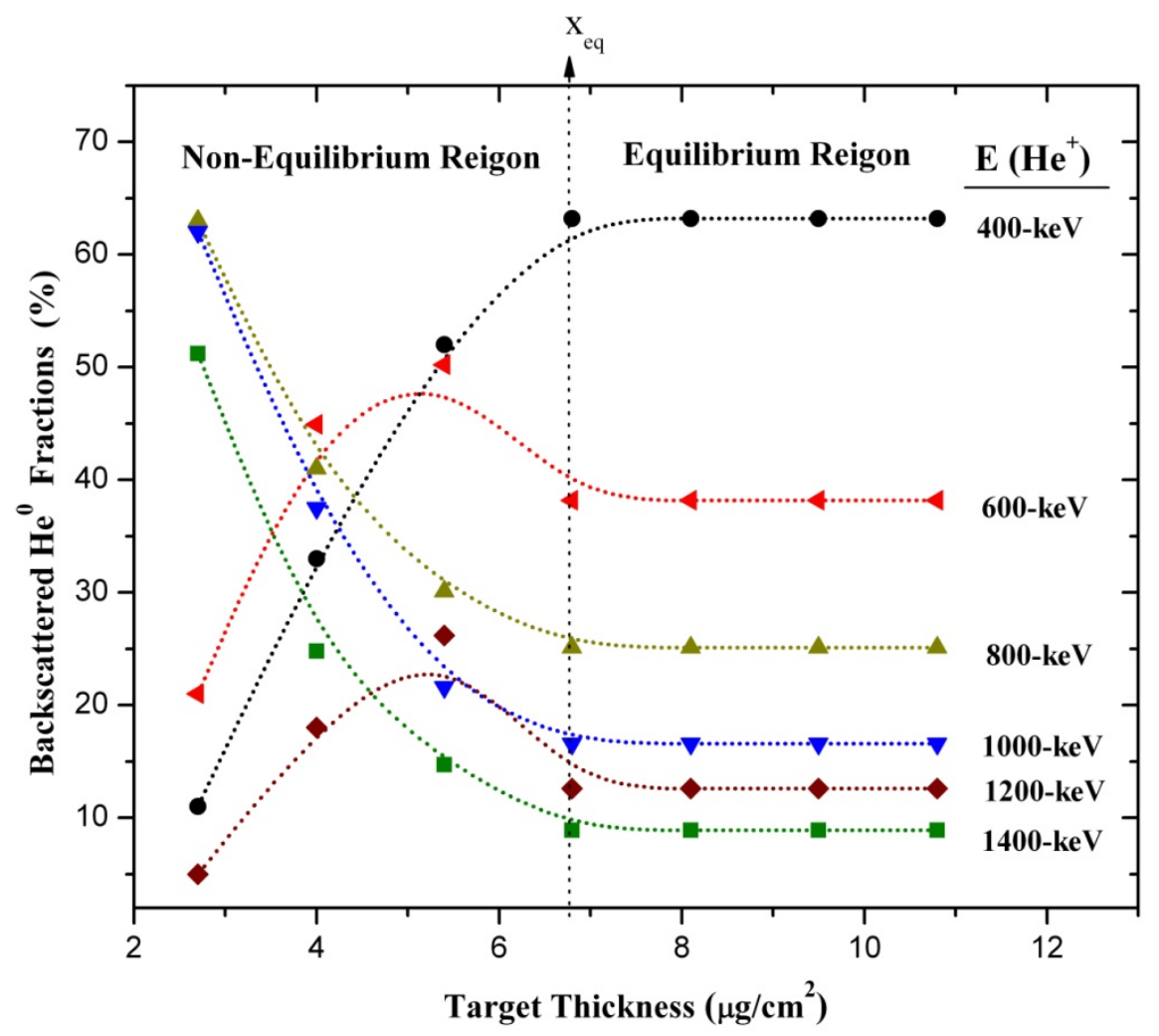

Figure 3. The measured $\mathrm{He}^{0}$ fractions at different projectile's energies plotted as a function of Al-foil thickness. Smooth dotted lines are drawn to guide the eyes.



Figure 4. The measured $\mathrm{He}^{+}$fractions at different projectile's energies plotted as a function of Al-foil thickness. Smooth dashed lines are drawn to guide the eyes. 




Figure 5. The measured $\mathrm{He}^{+2}$ fractions at different projectile's energies plotted as a function of Al-foil thickness. Smooth solid lines are drawn to guide the eyes.

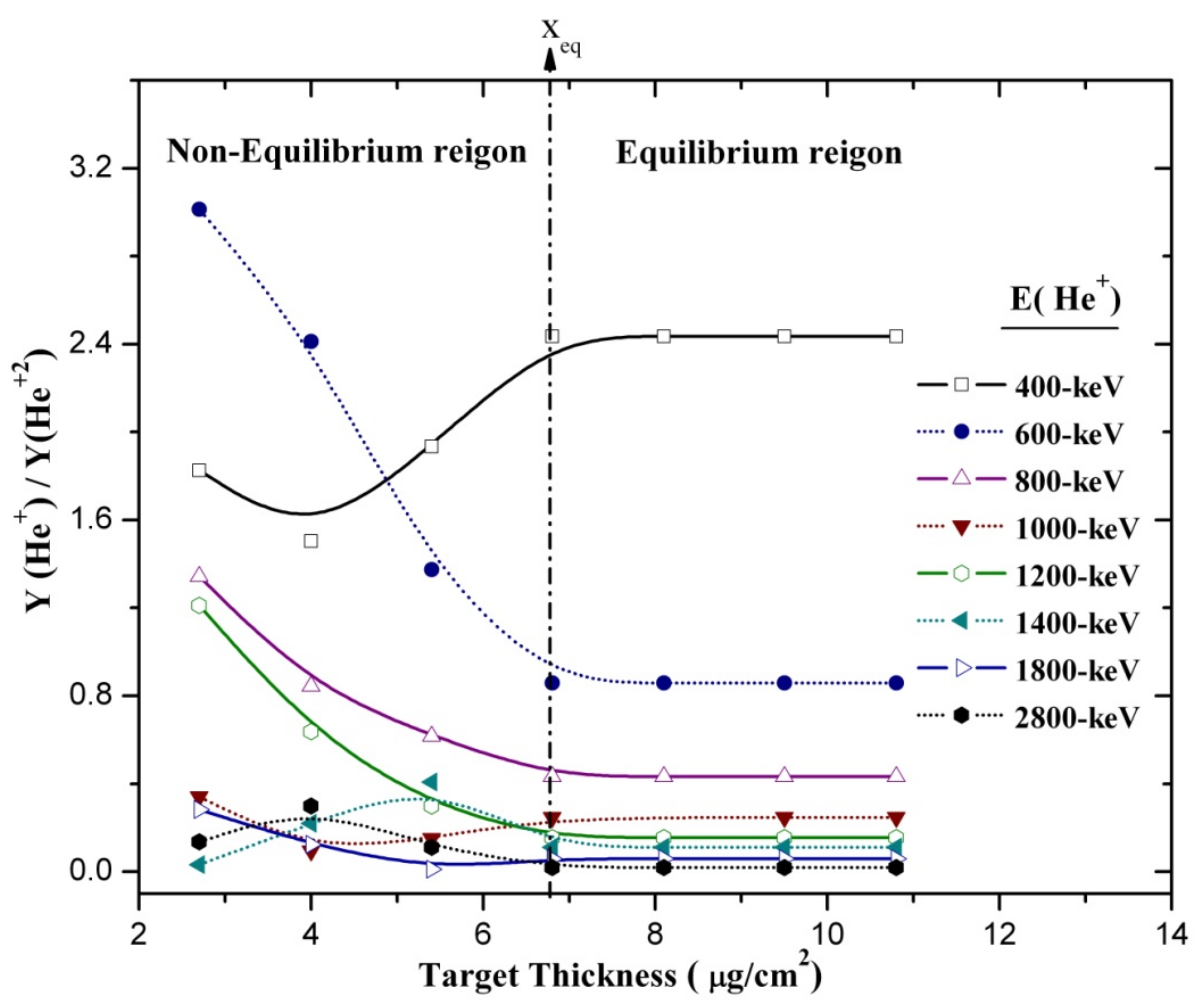

Figure 6. Ratios of singly ionized to doubly ionized ions in a helium beam which have reached charge state equilibrium in Al-foils of thicknesses $\geq 6.8 \mu \mathrm{g} . \mathrm{cm}^{-2}$ as a function of Al-foil thickness $\left(\mu \mathrm{g} / \mathrm{cm}^{2}\right)$. Ratios of singly to doubly ionized ions in non-equilibrium region (thicknesses $<6.8 \mu \mathrm{g} . \mathrm{cm}^{-2}$ ) are also plotted. The smooth dotted and solid lines are drawn to guide the eyes. 




Figure 7. Ratio of singly ionized to doubly ionized ions in a helium beam which has reached charge-state equilibrium in Al-foil of thickness of $8.1 \mu \mathrm{g} . \mathrm{cm}^{-2}$ as a function of projectile's velocity (a.u). The dotted, dashed and solid lines are the simulations based on Bohr model and Bianconi model.

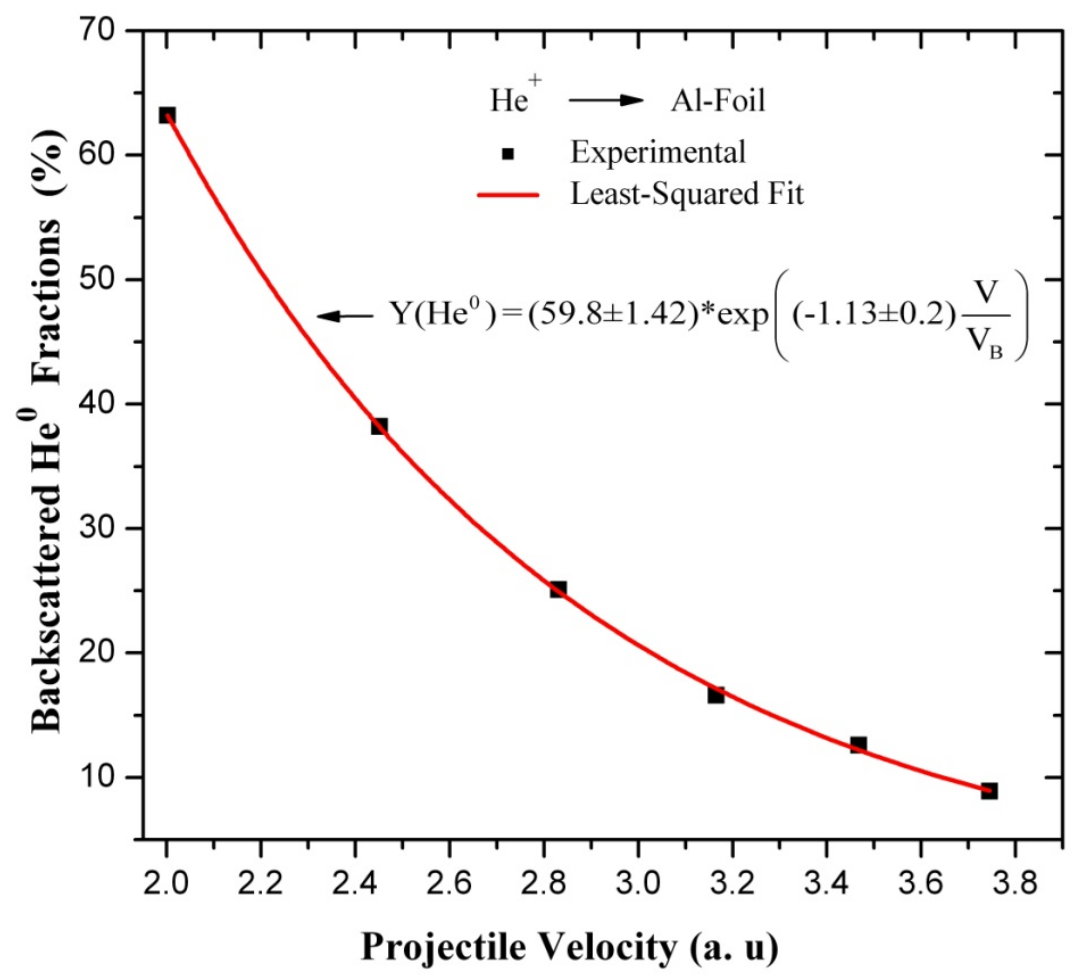

Figure 8. Charge-state fractions of $\mathrm{He}^{0}$ backscattered from $8.1 \mu \mathrm{g} . \mathrm{cm}^{-2} \mathrm{Al}$-foil as a function of projectile velocity:

(a) this work, the solid line is an empirical fit of the experimental data (Eq. 16) 


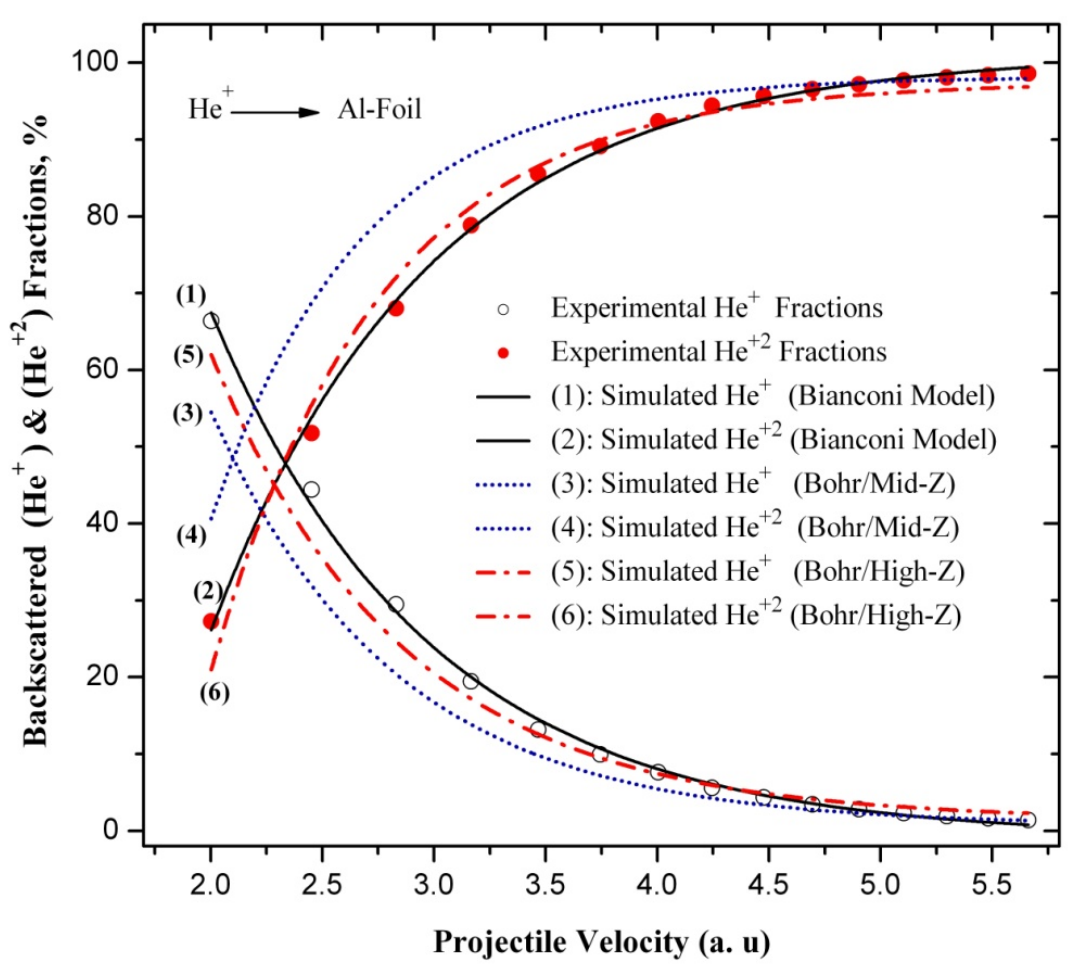

Figure 9. Singly and doubly charged fractions, $\mathrm{Y}\left(\mathrm{He}^{+}\right)$and $\mathrm{Y}\left(\mathrm{He}^{+2}\right)$, of the beam backscattered from the surface of Al-foil: the symbols (०) and $(\bullet)$ indicate the measured $\mathrm{He}^{+}$and $\mathrm{He}^{+2}$ fractions respectively. Solid, dotted and dashed lines are different calculations of $\mathrm{Y}\left(\mathrm{He}^{+}\right)$and $\mathrm{Y}\left(\mathrm{He}^{+2}\right)$ fraction based on the theory of Bohr (1948) and Bianconi et al (2002)

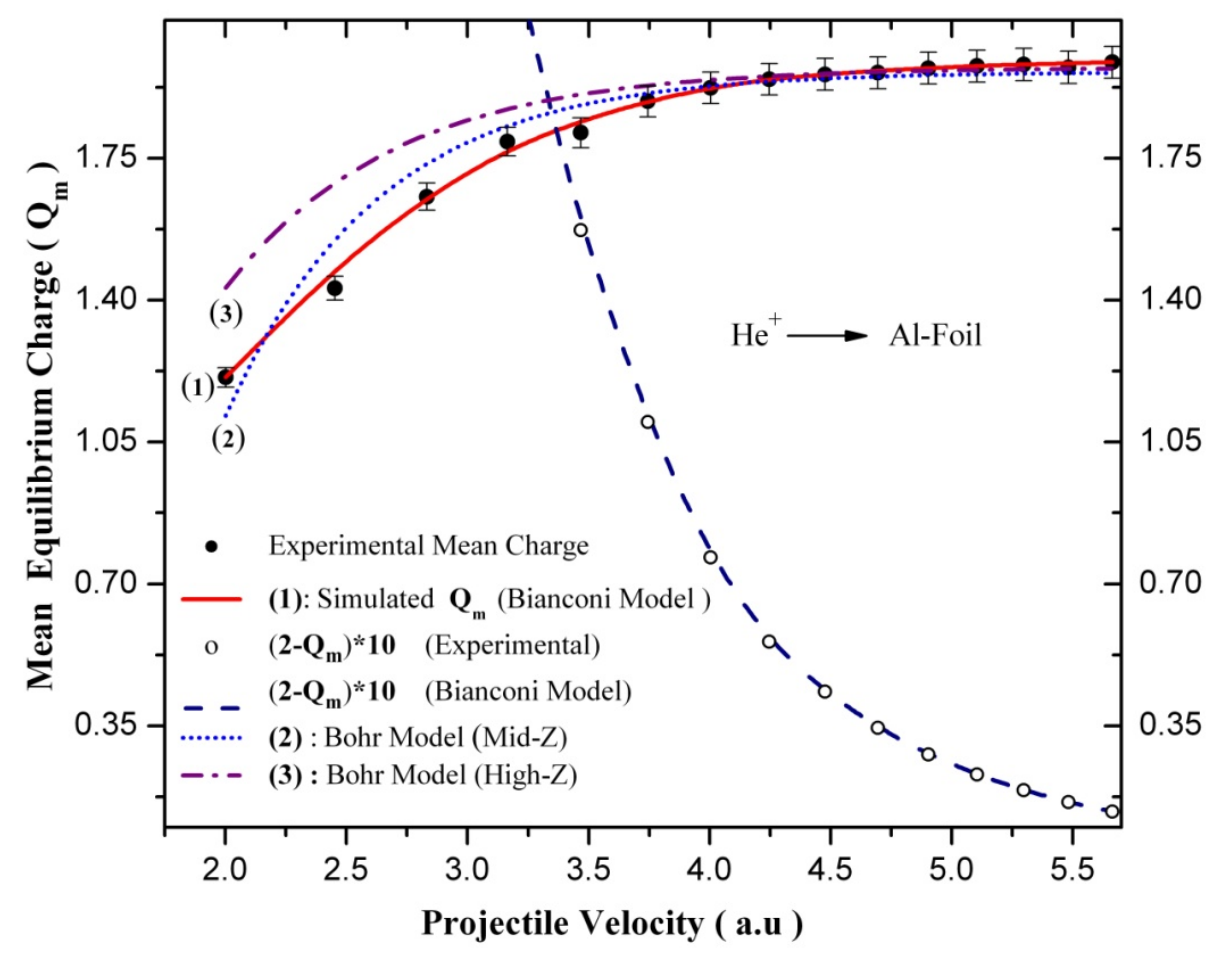

Figure 10. Mean equilibrium charge $\mathrm{Q}_{\mathrm{m}}$ (left scale) plotted against $\mathrm{He}^{+}$ion velocity (a. u). At high velocities, the fractional component is solely the doubly charged fraction. To assist evaluation at high velocities, $\left(2-\mathrm{Q}_{\mathrm{m}}\right) * 10$ is also plotted (right scale). 